\title{
Hair analysis following chronic smoked-drugs-of- abuse exposure in adults and their toddler: a case report
}

\author{
Esther Papaseit ${ }^{1,2,3}$, Xavier Joya $^{1,2,3}$, Marta Velasco ${ }^{3}$, Ester Civit ${ }^{1}$, Pau Mota ${ }^{3}$, Marta Bertran ${ }^{3}$, Oriol Vall ${ }^{1,2,3}$ and \\ Oscar Garcia-Algar ${ }^{1,2,3^{*}}$
}

\begin{abstract}
Introduction: Over the past two decades, the study of chronic cocaine and crack cocaine exposure in the pediatric population has been focused on the potential adverse effects, especially in the prenatal period and early childhood. Non-invasive biological matrices have become an essential tool for the assessment of a long-term history of drug of abuse exposure.

Case report: We analyze the significance of different biomarker values in hair after chronic crack exposure in a two-year-old Caucasian girl and her parents, who are self-reported crack smokers. The level of benzoylecgonine, the principal metabolite of cocaine, was determined in segmented hair samples $(0 \mathrm{~cm}$ to $3 \mathrm{~cm}$ from the scalp, and $>3 \mathrm{~cm}$ from the scalp) following washing to exclude external contamination. Benzoylecgonine was detectable in high concentrations in the child's hair, at $1.9 \mathrm{ng} / \mathrm{mg}$ and $7.04 \mathrm{ng} / \mathrm{mg}$, respectively. Benzoylecgonine was also present in the maternal and paternal hair samples at $7.88 \mathrm{ng} / \mathrm{mg}$ and $6.39 \mathrm{ng} / \mathrm{mg}$, and $13.06 \mathrm{ng} / \mathrm{mg}$ and $12.97 \mathrm{ng} /$ mg, respectively.

Conclusion: Based on the data from this case and from previously published poisoning cases, as well as on the experience of our research group, we conclude that, using similar matrices for the study of chronic drug exposure, children present with a higher cocaine concentration in hair and they experience more serious deleterious acute effects, probably due to a different and slower cocaine metabolism. Consequently, children must be not exposed to secondhand crack smoke under any circumstance.
\end{abstract}

\section{Introduction}

Since the mid-1990s, cocaine has been the second most popular illegal recreational drug in Europe among young adults and adolescents, the first being cannabis [1]. Similar to other illicit drugs, cocaine is commonly used by different routes of administration: orally, by smoking or chewing; parenterally; as a suppository; and, mainly, by snorting or inhalation of crack cocaine smoke. Free-base crack cocaine is a potent form of cocaine rapidly absorbed through the pulmonary circulation and reaching the central nervous system within seconds, which results in rapid and striking stimulant effects [2]. Its pharmacological action by smoking is

\footnotetext{
* Correspondence: 90458@hospitaldelmar.cat

'Programa de Recerca en Neurociències, IMIM (Institut de Recerca, Hospital del Mar), Parc de Salut Mar, Barcelona, Spain

Full list of author information is available at the end of the article
}

responsible for many of the reported neurological and pulmonary toxic effects $[3,4]$. Over the last 20 years, parallel to the advances in laboratory techniques for detecting recent drug use, hair analysis has emerged as the most important non-invasive biomarker used to provide long-term information on an individual's drug use [5-8]. Decontamination of hair samples by washing before analysis, detection of the relevant metabolites and use of adequate cut-off levels have been the main considerations in testing for drugs in hair [9]. The differentiation between systemic exposure and external contamination has been a controversial topic and one of the limitations of cocaine testing in hair [10-12]. In fact, hair exposed to crack cocaine by external contamination, where the individual does not actively consume the drug but traces may be deposited on the hair, must be carefully considered [13]. At present, hair analysis is

\section{C) Biomed Central}


used to monitor for drugs of abuse and environmental exposure to drugs of abuse [14]. In the pediatric population, hair screening has been used to determine gestational cocaine exposure $[15,16]$, detect unsuspected exposure to cocaine in children $[17,18]$ and confirm chronic cocaine exposure in cases of acute intoxication or high suspicion [19]. Similarly, in adults, cocaine hair screening is routinely applied to detect drug abuse in forensic cases, occupational and traffic medicine and clinical toxicology [14], including monitoring of cocaineabusing households by child welfare agencies in child custody cases.

To the best of our knowledge, there are no previous publications reporting on biomarker values in children's hair after chronic exposure to crack smoke and active abuse and exposure in adults. Here, we present a case of chronic exposure to cocaine through passive inhalation of crack cocaine smoke in a two-year-old girl as result of suspicion of environmental exposure to this drug of abuse by a pediatrician.

\section{Case presentation}

A two-year-old Caucasian girl was brought to our Pediatric Emergency Department, referred from a pediatric outpatient center for unclear reasons after presenting with respiratory symptoms for two weeks. Her medical records showed that she had been diagnosed with neonatal withdrawal syndrome, which required long term treatment with phenobarbital. At the outpatient center, she had been diagnosed with repeated bronchiolitis and she needed health care services from a pediatric pulmonologist, who prescribed treatment with fluticasone. She had no other relevant medical or pathological background.

Medical records informed us that the child's mother had a medical history of substance-related disorders and she was receiving treatment for heroin dependence with methadone. No other pharmacological treatment was prescribed for cannabis and tobacco abuse.

When attending our department, the mother presented an unhealthy aspect and abnormal behavior. A physical examination of the child showed a minor asthma attack with respiratory difficulties and clinical features refractory to the outpatient bronchodilator treatment (salbutamol) over the past 15 days. The examination also revealed use of her accessory muscles for respiration, wheezing and bilateral hypoventilation. Her blood oxygen saturation level was $98 \%$ and cyanosis was not observed. Her vital signs revealed tachycardia and tachypnea without fever (her heart rate was 148 beats per minute, her respiratory rate, 60 breaths per minute and temperature $36^{\circ} \mathrm{C}$ ). A neurological examination did not show a focal neurological deficit (15/15 Glasgow Score Scale) and the remainder of the physical examination was normal. The child received respiratory support and pharmacological treatment with gradual clinical improvement. Her blood cell count and serum biochemistry were normal. Under suspicion of exposure to drugs of abuse, urinary toxicology screening for commonly used drugs of abuse by cloned enzyme donor immunoassay (CEDIA, Microgenics, Barcelona, Spain) was done. Repeated urinary tests were positive for cocaine. Since urine toxicology was done in a pediatric emergency ward and speed was of paramount importance, the level of benzoylecgonine (BZG) in her urine was not quantified.

Information concerning the environment where the child had been living was obtained from the mother, who confirmed a history of crack smoking by both parents in the presence of the child during the days previous to her hospital admission. She denied that her child had ingested cocaine by any other route than passive inhalation. Chronic exposure to cocaine in an environment where drugs of abuse were being used by the parents was verified by hair analysis for the child and her parents (Table 1).

After 48 hours, our patient recovered completely without any respiratory difficulties. She was discharged from the hospital and the proper authorities were alerted in order to evaluate the child's home conditions.

In the present case, a quantitative analysis of cocaine, opiates, amphetamines, cannabis and 3,4-methylenedioxymethamphetamine (MDMA) in her hair was performed according to forensic standards using an immunoassay $\left(\mathrm{VMA} / \mathrm{DRI} \mathrm{I}^{\circledR}\right.$ ) on the available length of hair. The child's and her parent's hair samples (as an entire strand) were cut close to the scalp at the vertex region using stainless steel scissors. Whenever possible (hair shaft length more than $3 \mathrm{~cm}$ ), the hair strands were divided into subsequent $3 \mathrm{~cm}$ segments, each representing hair growth in subsequent three-month periods. To exclude external contamination, the samples were washed before testing.

A comprehensive toxicological screening was performed on the collected hair samples. The test was positive for BZG, the main metabolite of cocaine, and cannabis in the entire hair samples. Quantitative analysis confirmed that BZG was present in the child's hair at a concentration of $1.9 \mathrm{ng} / \mathrm{mg}$ and $7.04 \mathrm{ng} / \mathrm{mg}$. BZG concentrations found in her mother's and father's hair were $7.88 \mathrm{ng} / \mathrm{mg}$ and $6.39 \mathrm{ng} / \mathrm{mg}$, and $13.06 \mathrm{ng} / \mathrm{mg}$ and 12.97 $\mathrm{ng} / \mathrm{mg}$, respectively. Opiates were detected in her mother's hair. Amphetamines and MDMA were not detected.

\section{Discussion}

The information regarding passive postnatal toxic exposure to cocaine in children is limited. At our hospital, hair analysis in preschool children without signs 
Table 1 Hair segment concentration of drugs of abuse from the child and her parents using VMA/DRI ${ }^{\circledR}$.

\begin{tabular}{|c|c|c|c|}
\hline \multirow[t]{2}{*}{ Hair segments } & \multicolumn{3}{|c|}{ Drugs of abuse and metabolites in hair (cut off values) } \\
\hline & BZG $(0.50 \mathrm{ng} / \mathrm{mg})$ & Cannabis $(0.10 \mathrm{ng} / \mathrm{mg})$ & Opiates $(0.50 \mathrm{ng} / \mathrm{mg})$ \\
\hline \multicolumn{4}{|l|}{ Child's hair } \\
\hline $0 \mathrm{~cm}$ to $3 \mathrm{~cm}$ & 1.9 & 0.3 & ND \\
\hline$>3 \mathrm{~cm}$ & 7.04 & 0.7 & ND \\
\hline \multicolumn{4}{|l|}{ Mother's hair } \\
\hline $0 \mathrm{~cm}$ to $3 \mathrm{~cm}$ & 7.88 & 0.92 & 13.88 \\
\hline$>3 \mathrm{~cm}$ & 6.39 & 0.94 & 3.15 \\
\hline \multicolumn{4}{|l|}{ Father's hair } \\
\hline $0 \mathrm{~cm}$ to $3 \mathrm{~cm}$ & 13.06 & 0.28 & ND \\
\hline$>3 \mathrm{~cm}$ & 12.97 & 0.86 & ND \\
\hline
\end{tabular}

BZG: benzoylecgonine; ND: none detected

or symptoms suggestive of exposure revealed an estimated prevalence of exposure of $23.3 \%$ [17]. There are several clinical case reports detailing concentrations of BZG in the hair of children with parents using cocaine who are exposed to a contaminated environment, with considerable clinical findings (neurological and respiratory abnormalities), fatal poisonings by active ingestion (by hand-to-mouth activity) of powder residues $[20,21]$ or passive crack smoke inhalation [22-24].

Table 2 Cases reports of acute intoxication in children exposed passively to cocaine and confirmed by hair analysis.

\begin{tabular}{|c|c|c|c|}
\hline & Age & Chronic exposure & Benzoylecgonine in hair determined by gas chromatography/mass spectrometry (GC/MS) (ng/mg) \\
\hline \multirow[t]{5}{*}[25]{} & 11 months & Cocaine & Infant's hair \\
\hline & & & $1 \mathrm{~cm}$ to $4 \mathrm{~cm}: 0.4$ \\
\hline & & & $4 \mathrm{~cm}$ to $8 \mathrm{~cm}: 10.5$ \\
\hline & & & Mother's hair \\
\hline & & & $1 \mathrm{~cm}$ to $10 \mathrm{~cm}$ : negative for any illicit substance (bleached hair) \\
\hline \multirow[t]{13}{*}[26]{} & 15 months & Cocaine & Infant's hair \\
\hline & & & $1 \mathrm{~cm}$ to $2 \mathrm{~cm}: 2.2$ \\
\hline & & & $2 \mathrm{~cm}$ to $7 \mathrm{cm:} 7.6$ \\
\hline & & & Sister's hair \\
\hline & & & $1 \mathrm{~cm}$ to $2 \mathrm{~cm}$ : negative \\
\hline & & & $2 \mathrm{~cm}$ to $7 \mathrm{cm:} 0.5$ \\
\hline & & & $7 \mathrm{~cm}$ to $20 \mathrm{~cm}: 1.2$ \\
\hline & & & Mother's hair \\
\hline & & & $1 \mathrm{~cm}$ to $2 \mathrm{~cm}: 8.2$ \\
\hline & & & $2 \mathrm{~cm}$ to $7 \mathrm{~cm}: 5.3$ \\
\hline & & & $7 \mathrm{~cm}$ to $20 \mathrm{~cm}: 10.6$ \\
\hline & & & Father's hair \\
\hline & & & $1 \mathrm{~cm}$ to $2 \mathrm{~cm}: 3.0$ \\
\hline \multirow[t]{3}{*}[27]{} & 24 months & & Infant's hair \\
\hline & & & $0 \mathrm{~cm}$ to $1 \mathrm{~cm}: 1.9$ \\
\hline & & & $1 \mathrm{~cm}$ to $15 \mathrm{~cm}: 17.2^{\mathrm{a}}$ \\
\hline \multirow[t]{2}{*}{ [28] } & 13 months & Cocaine & Infant's hair \\
\hline & & & 0.6 \\
\hline \multirow[t]{6}{*}{ [29] } & One month & Cocaine & Infant's hair \\
\hline & & & 2.2 \\
\hline & & & Mother's hair \\
\hline & & & 3.4 \\
\hline & & & Father's hair \\
\hline & & & 1.7 \\
\hline
\end{tabular}


In this case report the appearance of the family and their medical records, in addition to the clinical features presented by the child, suggested the possibility of an unhealthy environment and consequently intoxication with drugs of abuse. Her exposure to cocaine in the days preceding her admission was confirmed by an initial positive urinary immunoassay, in addition to symptoms suggesting recent exposure to crack cocaine smoke.

Under the circumstances, analysis of the child's and parent's hair was performed in order to assess previous and chronic exposure to cocaine and other illicit drugs (the clinical consequences of a polyexposure can be very serious). The BZG concentrations found in the proximal and distal extremities of our patient's hair demonstrated repeated exposure to environmental cocaine at least during the last three months. Therefore, the need to be admitted at the pediatric emergency, the medical background of the child and the presence of BZG in her hair can be all explained by a systematic passive exposure to crack cocaine smoke. The BZG concentration in her hair was proportionally higher than the BZG concentration in her parent's hair, who actively smoked crack cocaine. Considering this child's age, the results suggest that passive environmental exposure in young children may have highly toxic, even potential lethal, effects, probably due to their immature metabolizing capacity. In fact, previous cases of symptomatic chronic intoxication by cocaine have been described, but with lower concentration of cocaine in hair in comparison with adult hair concentrations [25-29].

Based on the data from this case and other poisoning cases published by our group and other groups (Table 2) [25-29], we conclude that parental use of cocaine can be reflected in a non-negligible exposure of their progeny, and children show higher concentrations of cocaine in hair and they experience more serious deleterious acute effects, perhaps due to different and slower cocaine metabolism.

\section{Conclusion}

We conclude that passive exposure to smoked cocaine must be strictly avoided in infants and children. In addition, drug testing in conventional (urine and blood) and non-conventional (hair) matrices should be used routinely in all the children who present with specific or suspicious symptoms of acute and/or chronic exposure to illicit drugs, particularly with suspected drug-using parents, frequently polyusers. Once again, hair analysis proved to be a useful tool in disclosing chronic exposure to drugs of abuse. Furthermore, hair analysis offers the opportunity to periodically examine drug exposure in order to protect these children from significant health and social risks. We advocate hair analysis in all cases of newborns, toddlers and children from risky environments.

\section{Consent}

Written informed consent was obtained from our patient's parents (her legal guardians) for publication of this case report and any accompanying images. A copy of the written consent is available for review by the Editor-in-Chief of this journal.

\section{Author details}

${ }^{1}$ Programa de Recerca en Neurociències, IMIM (Institut de Recerca, Hospital del Mar), Parc de Salut Mar, Barcelona, Spain. ${ }^{2}$ Grup de Recerca i Entorn (GRIE), Institut de Recerca, Hospital del Mar, Parc de Salut Mar, Barcelona, Spain. ${ }^{3}$ Universitat Autónoma de Barcelona, Barcelona, Spain.

\section{Authors' contributions}

EP was the main contributor in writing the manuscript. XJ was an important laboratory technician in biomarkers analyses, and contributed in writing the manuscript. MV analyzed the mother-infant data, reviewed the literature and the final manuscript, and contributed in writing the manuscript. EC was the main laboratory technician in biomarkers analyses. PM analyzed the motherinfant data, and was a contributor in writing the manuscript. MB analyzed the mother-infant data, and was the statistical expert. OV was the pediatrician responsible for coordination of data, and contributed in writing the manuscript. OGA analyzed the mother-infant data, reviewed the literature, and was a major contributor in writing the manuscript. All authors have read and approved the final manuscript.

\section{Competing interests}

The authors declare that they have no competing interests.

Received: 2 August 2011 Accepted: 10 December 2011

Published: 10 December 2011

\section{References}

1. Smart RG: Crack cocaine use: a review of prevalence and adverse effects. Am J Drug Alcohol Abuse 1991, 17:13-26.

2. Haim DY, Lippmann ML, Goldberg SK, Walkenstein MD: The pulmonary complications of crack cocaine. A comprehensive review. Chest 1995, 107:233-240.

3. Hirche TO, Lambrecht E, Wagner TO: Crack-syndrome: the pulmonary complications of inhaled cocaine. A review a propos a case report. Pneumologie 2002, 56:684-648, [in German].

4. Perper JA, van Thiel DH: Respiratory complications of cocaine abuse. Recent Dev Alcohol 1992, 10:363-377.

5. Barroso M, Gallardo E, Queiroz JA: Bioanalytical methods for the determination of cocaine and metabolites in human biological samples. Bioanalysis 2009, 1:977-1000.

6. Kintz P, Villain M, Cirimele V: Hair analysis for drug detection. Ther Drug Monit 2006, 28:442-446.

7. Pragst $F$, Balikova MA: State of the art in hair analysis for detection of drug and alcohol abuse. Clin Chim Acta 2006, 370:17-49.

8. García-Algar O, Papaseit E, Velasco M, López N, Martínez L, Luaces C, Vall O: Drugs of abuse acute intoxication in paediatric emergencies. An Pediatr (Barc) 2011, 74:413-416.

9. Tsanaclis L, Wicks JF: Differentiation between drug use and environmental contamination when testing for drugs in hair. Forensic Sci Int 2008, 176:19-22.

10. Koren G, Klein J, Forman R, Graham K: Hair analysis of cocaine: differentiation between systemic exposure and external contamination. J Clin Pharmacol 1992, 32:671-675.

11. Mieczkowski T: Distinguishing passive contamination from active cocaine consumption: assessing the occupational exposure of narcotics officers to cocaine. Forensic Sci Int 1997, 84:87-111.

12. Romano G, Barbera N, Lombardo I: Hair testing for drugs of abuse: evaluation of external cocaine contamination and risk of false positives. Forensic Sci Int 2001, 123:119-129.

13. Boumba VA, Ziavrou KS, Vougiouklakis T: Hair as a biological indicator of drug use, drug abuse or chronic exposure to environmental toxicants. Int J Toxicol 2006, 25:143-163. 
14. Karacic V, Skender L: Hair testing for drugs of abuse. Coll Antropol 2003, 27:263-269.

15. Graham K, Koren G, Klein J, Schneiderman J, Greenwald M: Determination of gestational cocaine exposure by hair analysis. JAMA 1989, 262:3328-3330.

16. Callahan CM, Grant TM, Phipps P, Clark G, Novack AH, Streissguth AP, Raisys VA: Measurement of gestational cocaine exposure: sensitivity of infants' hair, meconium, and urine. J Pediatr 1992, 120:763-768.

17. Joya X, Papaseit E, Civit E, Pellegrini M, Vall O, Garcia-Algar O, Scaravelli G, Pichini S: Unsuspected exposure to cocaine in preschool children from a Mediterranean city detected by hair analysis. Ther Drug Monit 2009, 31:391-395

18. Garcia-Bournissen F, Nesterenko M, Karaskov T, Koren G: Passive environmental exposure to cocaine in Canadian children. Pediatric Drugs 2009, 11:30-32.

19. Klein J, Karaskov T, Koren G: Clinical applications of hair testing for drugs of abuse-the Canadian experience. Forensic Sci Int 2000, 107:281-288.

20. Press S: Crack and fatal child abuse. JAMA 1988, 260:3132.

21. Bateman DA, Heagarty MC: Passive freebase cocaine ('crack') inhalation by infants and toddlers. Am J Dis Child 1989, 143:25-27.

22. Schwartz RH: Passive inhalation of marijuana, phencyclidine, and freebase cocaine ("crack") by infants. Am J Dis Child 1989, 143:644

23. Heidemann SM, Goetting MG: Passive inhalation of cocaine by infants. Henry Ford Hosp Med J 1990, 38:252-254.

24. Mirchandani HG, Mirchandani IH, Hellman F, English-Rider R, Rosen S, Laposata EA: Passive inhalation of free-base cocaine ('crack') smoke by infants. Arch Pathol Lab Med 1991, 115:494-498.

25. Garcia-Algar O, López N, Bonet M, Pellegrini M, Marchei E, Pichini S: 3,4methylenedioxymethamphetamine (MDMA) intoxication in an infant chronically exposed to cocaine. Ther Drug Monit 2005, 27:409-411.

26. Garcia-Algar O, López-Vílchez MA, Pacifici R, Pichini S: Acute poisoning and chronic exposure to cocaine in a child. Med Clin (Barc) 2005, 125:436-437, [in Spanish].

27. Taguchi N, Mian M, Shouldice M, Karaskov T, Gareri J, Nulman I, Verjee ZH, Koren G: Chronic cocaine exposure in a toddler revealed by hair test. Clin Pediatr (Phila) 2007, 46:272-275.

28. Papaseit E, Corrales E, Stramesi C, Vall O, Palomeque A, Garcia-Algar O: Postnatal methadone withdrawal syndrome: hair analysis for detecting chronic exposure. Acta Paediatr 2010, 99:162-163.

29. Joya X, Friguls B, Simó M, Civit E, de la Torre R, Palomeque A, Vall O, Pichini S, Garcia-Algar O: Acute opioid intoxication in an infant cronically exposed to cocaine and heroin. J Med Case Reports 2011, 5:288.

doi:10.1186/1752-1947-5-570

Cite this article as: Papaseit et al:: Hair analysis following chronic smoked-drugs-of-abuse exposure in adults and their toddler: a case report. Journal of Medical Case Reports 2011 5:570.

\section{Submit your next manuscript to BioMed Central and take full advantage of:}

- Convenient online submission

- Thorough peer review

- No space constraints or color figure charges

- Immediate publication on acceptance

- Inclusion in PubMed, CAS, Scopus and Google Scholar

- Research which is freely available for redistribution

Submit your manuscript at www.biomedcentral.com/submit
Biomed Central 